\title{
Ocular changes in reactions in leprosy
}

\author{
P SHOREY*, M M KRISHNAN*, S DHAWAN* \& \\ B R GARG $\dagger$ \\ Departments of Ophthalmology* and Dermatology $\dagger$, Jawaharlal \\ Institute of Postgraduate Medical Education and Research, Pondi- \\ cherry-605 006, India
}

\section{Accepted for publication 30 December 1988}

\begin{abstract}
Summary A study of ocular changes in reactions in leprosy was undertaken to assign these changes, their proper place in the wide spectrum of ocular morbidity in leprosy. $76 \cdot 1 \%$ of eyes of Type I reaction and $89.7 \%$ of eyes with Type II reaction showed some ocular involvement. Corneal hypoaesthesia, superficial punctate keratitis, a decrease of corneal film break up time (BUT), prominent corneal nerves, pigment on the endothelium of the cornea and a pigmented trabecular meshwork were the common ocular findings. The incidence of iridocyclitis in Type II reactions was low $(8 \cdot 1 \%)$. The significance of the ocular involvement in reactions in leprosy and the pathogenesis of iridocyclitis in Type II reactions is discussed.
\end{abstract}

\section{Introduction}

Ocular leprosy presents a formidable challenge to the leprologist as it is still responsible for some of the most distressing aspects of the disease. Around one million people of the world's leprosy population are blind. ${ }^{1}$

The potentially sight-threatening lesions of leprosy are iridocyclitis and its sequelae; corneal anaesthesia, exposure keratitis due to lagophthalmos, leprous keratitis, scleritis and secondary glaucoma. ${ }^{2,3}$

Leprosy patients may suffer from a variety of reactions, the most common being the reversal reaction (Type I) and the erythema nodosum leprosum (Type II). Reversal reactions are episodes of increased inflammatory activity in the skin lesions, peripheral nerves or both. Type II reactions are generated against intravascular and extravascular immune complexes and are characterized by acute inflammations in any organ or tissue where the Mycobacterium leprae are found.

Though textbooks on leprosy cover the ocular changes in reactions in leprosy, ${ }^{1,4}$ as yet, there has been no systematic study of these changes. Some reports are anecdotal, ${ }^{5,6}$ while others are by nonophthalmologists where the assessment of the eye may not have been adequate..$^{7,8}$

We undertook a study of the incidence of the ocular changes in reactions in leprosy so that these changes could be assigned their proper place in the wide spectrum of ocular morbidity in leprosy. 
The study was initiated in 1986 by examining 32 consecutive leprosy patients in reaction, who had reported to the hospital for the first time and had not undergone any prior treatment for reactions.

\section{Patients and methods}

The patients in this study come from Pondicherry and its adjoining areas where the prevalence rate of leprosy is 10 or more per $1000 .{ }^{9}$ The study was conducted by the Departments of Ophthalmology and Dermatology at JIPMER, Pondicherry, India. Thirty-two patients of leprosy in reaction were included in this study. The classification of leprosy by Ridley and Jopling was followed. Only those patients were taken up in this study, who were not on any treatment for the reactions at the time of the first examinations. The patients were evaluated by the dermatologist for the type of leprosy, its duration, the treatment taken; the type of reaction, the number and duration of reaction.

The eyes of these patients were examined in the following order: 1, ocular history; 2 , visual acuity; 3, external examination of the anterior segment of the eye; 4, corneal sensations; 5 , slit lamp examination; 6, corneal film break up time (BUT); 7, applanation tension; 8, gonioscopy; 9, near point of accommodation by RAF rule; 10 , study of pupils; 11 , fundus examination.

The methodology of Cochet and Bonnet was followed in the measurement of corneal sensations by Cochet-Bonnet Aesthesiometer. ${ }^{10}$ Goldmann applanation tonometer and Goldmann 3 mirror lens were used for applanation tonometry and gonioscopy respectively.

The test for BUT was done on the slit lamp. The tear film was stained by fluorescein $2 \%$ and the time taken for the first dry spot to appear on the cornea after the last blink was noted.

The near point of accommodation was studied by the RAF rule, an instrument used to determine the power and near point of accommodation.

The method of Swift \& Bauschard " was followed to study the pupillary reactions to adrenaline. The initial size of the pupil was noted by Cogan's pupillometery. ${ }^{12}$ Two drops of $1 \%$ adrenaline were instilled in the conjunctival sac of both eyes and the pupil size was noted after $30 \mathrm{~m}$. A response was considered positive if the pupil dilated by $0.3 \mathrm{~mm}$ or more over control values.

The control group comprised of 30 normal eyes of 15 patients of comparable age and sex, attending the outpatient Ophthalmic Department.

\section{Results}

There were 26 males and 6 females. The age variation was from 13 to 57 years (mean age $29 \cdot 4$ years). The duration of leprosy varied from 1 month to 6 years (mean duration 2.5 years). There were 25 patients of lepromatous leprosy and 7 patients of borderline-tuberculoid leprosy. There were 7 patients with Type I reaction and 25 patients with Type II reaction.

Sixty-two eyes of 32 patients were examined. Twoeyes were excluded from the study as one had an adherent leucoma and the other had gone into pthisis due to trauma. Thirteen eyes $(20.9 \%)$ were seen in patients having Type I reaction and 49 eyes (79.1\%) were examined in patients of Type II reactions. Ocular involvement was seen in 10 eyes (76.9\%) of Type I reaction and 44 eyes $(89 \cdot 7 \%)$ of Type II reaction (Table 1).

Visual acuity was decreased in only one eye with Type II reaction due to acute iridocyclitis. Erythematous plaques on the upper or lower lids were seen in 4 eyes $(30 \cdot 7 \%)$ of Type I reaction and in only 2 eyes $(4 \cdot 1 \%)$ of Type II reaction. Mild lagophthalmos was seen in 2 eyes with Type II reaction.

The cornea showed prominent corneal nerves and pigment on the corneal endothelium in both types of reaction. A peculiar pigment migration on the lower half of the corneal epithelium was seen in 6 eyes $(12 \cdot 2 \%)$ of Type II reaction. Superficial punctate keratitis was seen in $67 \cdot 3 \%$ of eyes in Type II reaction. The corneal sensations as measured by Cochet-Bonnet aesthesiometer revealed a slight 
Table 1. Summary of ocular changes

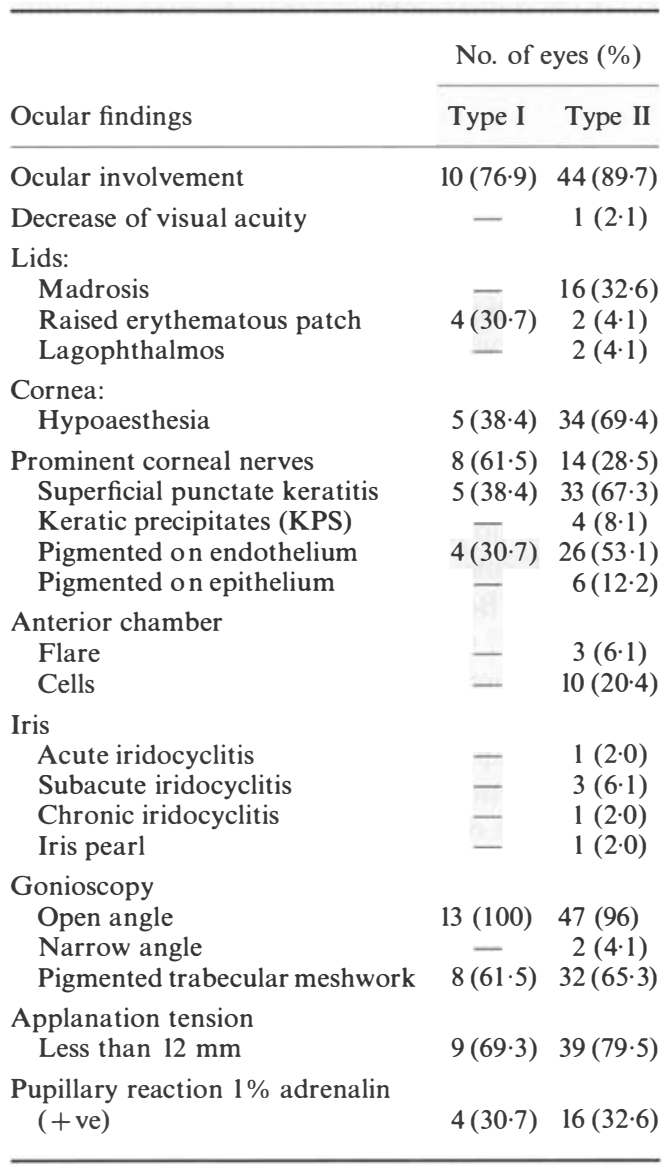

to marked decrease in 34 eyes $(69 \cdot 8 \%)$ of Type II reactions (Table 2). An abnormal BUT was seen in all eyes with 34 eyes $(69 \cdot 8 \%)$ of Type II reaction showing a BUT of $0-5 \mathrm{~s}$ (Table 3 ).

Acute iridocylitis was seen in only one eye $(2 \%)$. Three eyes $(6 \cdot 1 \%)$ showed a subacute iridocyclitis while one eye showed evidence of old healed iridocyclitis. This was seen in Type II reactions only.

An applanation tension of less than $12 \mathrm{~mm}$ of mercury was exhibited in $79 \cdot 5 \%$ of eyes of Type II reaction and $69 \cdot 3 \%$ of eyes with Type I reaction.

Gonioscopy revealed a pigmented trabecular meshwork in 32 eyes $(65.3 \%)$ of Type II reaction and 8 eyes $(61.5 \%)$ of Type I reaction. The age matched control group of 30 eyes revealed a pigmented trabecular meshwork in $20 \%$ of the eyes.

There was no significant difference in the near point of accommodation of 26 patients below the age of 40 years with the aged-matched control group of 15 patients.

The pupillary reaction to $1 \%$ adrenaline was found to be positive in 4 eyes $(30.7 \%)$ with Type I reaction and 16 eyes $(32 \cdot 6 \%)$ with Type II reaction. In the control group a positive pupil reaction to $1 \%$ adrenaline was seen in 2 eyes $(6 \cdot 6 \%)$. The fundus examination was normal in all the eyes. 
Table 2. Corneal sensations as measured by Cochet-Bonnet aesthesiometer

\begin{tabular}{lll}
\hline & \multicolumn{2}{c}{ No. of eyes (\%) } \\
\cline { 2 - 3 } $\begin{array}{l}\text { Corneal sensation* } \\
\text { measurement }\end{array}$ & Type I & Type II \\
\hline $\begin{array}{l}\text { Normal } \\
\text { (No unit decrease) }\end{array}$ & $7(71 \cdot 6)$ & $15(30 \cdot 6)$ \\
$\begin{array}{l}\text { Slightly low } \\
\text { (One unit decrease) }\end{array}$ & $6(28 \cdot 4)$ & $10(20 \cdot 4)$ \\
$\begin{array}{l}\text { Moderately low } \\
(2 \text { unit decrease) } \\
\begin{array}{c}\text { Markedly low } \\
\text { (More than 2 unit decrease) }\end{array}\end{array}$ & - & $7(14 \cdot 2)$ \\
\hline \begin{tabular}{l} 
Total \\
\hline
\end{tabular} & $13(100)$ & $49(100)$ \\
\hline
\end{tabular}

* Ref er to table given with the aesthesiometer.

Table 3. Tear film break up time (BUT)

\begin{tabular}{lcc}
\hline & \multicolumn{2}{c}{ No. of eyes (\%) } \\
\cline { 2 - 3 } BUT (s) & Type I & Type II \\
\hline $0-5$ & $6(46 \cdot 2)$ & $34(69 \cdot 4)$ \\
$6-10$ & $5(38 \cdot 4)$ & $13(26 \cdot 5)$ \\
$11-15$ & $2(15 \cdot 3)$ & $2(4 \cdot 1)$ \\
16 & - & - \\
\hline Total & $13(100)$ & $49(100)$ \\
\hline
\end{tabular}

\section{Discussion}

Most of the deformities of leprosy result from a fairly acute inflammatory reaction. More than half the number of leprosy patients exhibit this reaction at some time during the course of this disease. ${ }^{13}$

In our study there was no statistically significant correlation between the number and duration of attacks of reaction with any of the ocular complications. Ocular involvement was common in both types of reaction (76.9\% in Type I and $89.7 \%$ in Type II). But considering the mean duration of leprosy ( 2.5 years) in our study, the ocular involvement was fairly high. Reactions in leprosy may accelerate the onset of ocular complications because the incidence of ocular involvement in leprosy is usually proportional to the known duration of leprosy and is infrequent during the first few years of the disease. ${ }^{2}$

Though the sample of eyes studied in Type I reaction was small, it revealed that the increased inflammatory activity also affected the ocular structures. The common ocular changes found were raised erythematous plaques on lids, corneal hypoaesthesia, superficial punctate keratitis, prominent corneal nerves, pigment on the endothelium of cornea and pigmented trabecular meshwork.

Madrosis, corneal hypoaesthesia, superficial punctate keratitis, a decrease in BUT, prominent corneal nerves, pigment on endothelium of cornea and pigmented trabecular meshwork were seen in Type II reactions. 
Decrease of corneal sensations was more common in Type II reactions $(67 \cdot 3 \%)$ as compared to Type I reaction (38.4\%). Superficial punctate keratitis paralleled the decrease of corneal sensations. BUT was found to be markedly decreased in Type II reaction $(69 \cdot 4 \%)$. Lamba et al. ${ }^{14}$ found an abnormal BUT in $47 \cdot 2 \%$ of patients with leprosy and attributed it to sympathetic denervation which produced an abnormal mucin layer of the tear film. Regression analysis of our results revealed a statistically significant correlation between decrease of corneal sensations and a decrease of corneal BUT (Figure 1). When the corneal sensations are normal, the tear film drying stimulates blinking and renewal of tear film, but when the corneal sensations get reduced blinking is delayed, hence the corneal BUT is decreased. ${ }^{15}$ Further evaluation is required to establish the relationship of corneal hypoaesthesia in reactions to subsequent corneal changes in leprosy patients.

Denervation hypersensitivity of the pupil to $1 \%$ adrenaline was revealed in $30.7 \%$ of eyes in Type I reaction and $32 \cdot 6 \%$ of eyes with Type II reaction. Swift \& Bauschard ${ }^{11}$ showed a $64 \cdot 2 \%$ incidence of hypersensitivity of the pupil to $1 \%$ adrenaline in patients with Type II reaction. Postganglionic sympathetic nerve dysf unction of the iris has been suggested as the possible cause of this phenomenon. ${ }^{11}$

The significance of pigment on the corneal endothelium and pigmented trabecular meshwork is difficult to assess. There is scant literature on gonioscopic findings in leprosy patients hence further studies are required to find out, if a difference exists in the gonioscopic findings between patients who are in reaction and the general leprosy patients. Increased pigmentation may be a sign of silent iritis representing a slow breakdown of the iris muscle following autonomic denervation. ${ }^{16}$

The incidence of iridocyclitis in ENL (Type II) reactions in our study was low $(8 \cdot 1 \%)$. Previous reports also reveal a low incidence despite the fact that no slit lamp examination was done in these cases. Rea et $\mathrm{l}^{17}$ found no eye signs in 32 patients in ENL reaction. Two studies ${ }^{7,8}$ found a $12 \%$ and $3 \%$ incidence of iridocyclitis respectively. Swift \& Bauschard ${ }^{11}$ who studied 13 patients of ENL found iritis in only 2 patients $(15.4 \%)$. The general belief that the ENL reactions are usually associated with iridocyclitis is refuted by our findings.

The pathogenesis of iridocyclitis in ENL reactions is still obscure. ENL reactions are associated with immune complexes of which the $M$. leprae antigen is a component. The antigen-antibody ratio

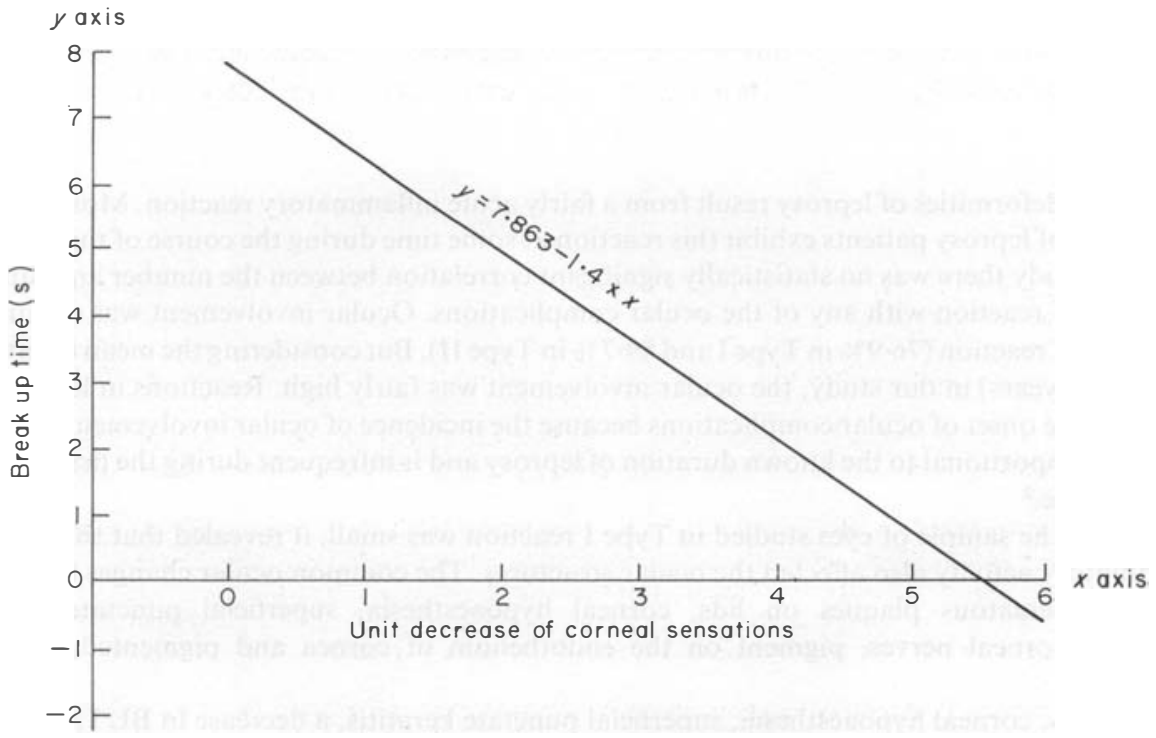

Figure 1. The unit decrease in corneal sensations shows significant correlation to decrease in corneal BUT. $y=7 \cdot 863-1 \cdot 4 x$. 
is one of the many factors that determine the localization and deposition of the immune complexes. ENL may be precipitated if the antigen-antibody ratio is balanced or if there is a slight antigen excess. Thus, the lesions whether in the skin or other tissues that go into reaction are presumably those in which the amount of free antigen is appropriate to the antibody level at the site. ${ }^{18}$

In experimental models of lens induced uveitis, pathological changes consistent with immune complex formation have been described. ${ }^{19}$ Increased vascular permeability, an essential feature of experimental uveitis, can be produced experimentally by intravenous injection of immune complexes. ${ }^{20}$

In lepromatous patients, large amounts of mycobacterial antigen are present within the macrophages for a long period of time being effectively separated from the precipitating antibodies occurring at the same time in the blood and interstitial fluid. ${ }^{21}$ Hashizuma et al ${ }^{22}$ in electron microscopic studies have demonstrated $M$. leprae laden macrophages in iris stroma, smooth muscle of iris and pigment epithelium. Thus, acute iridocyclitis in ENL reactions may be precipitated when an equilibrium is reached of the antigen-antibody ratio mediated by a disintegration of macrophages, resulting in deposition of immune complexes in the uveal tissue.

There is much individual variation in the onset of ENL from person to person and from one lesion to the other. ${ }^{18}$ The same corollary can be extended in explaining the low incidence of iridocyclitis in our study. It is not possible to say why most of the eyes of patients with ENL reactions do not react but a host of factors like blood flow, vascular permeability, antigen affinity for the uveal tissue, decrease of $\mathrm{T}$ suppressor cell population may orchestrate a uveal reaction individually or in unison. ${ }^{1,5,13,18}$

Since more than $50 \%$ of patients with leprosy go into reaction during the course of their infection, it seems probable that reactions sensitize the uveal tissue and lay the foundation for the future edifice of uveitis, the cause par excellence of blindness in leprosy. ${ }^{23}$

Ocular complications in reactions in leprosy may vary in severity in different parts of the world, being more severe in colder climates. ${ }^{1}$ As the mean duration of leprosy in our study was 2.5 years and the patients come from a tropical country, the ocular complications in a majority of cases did not cause any sight-threatening lesions. But sight-threatening ocular complications should be expected in patients in reaction who have a duration of leprosy of 10 years or more.

In conclusion, reactional states of leprosy may hasten the onset of ocular complications. These complications may be the precursors to sight-threatening lesions like keratitis and uveitis and may push the unfortunate leprosy patients in reaction to an earlier ocular morbidity than is normally the case.

\section{References}

${ }^{1}$ Brand ME, ffytche TF. Eye complications in leprosy. In Leprosy, Hastings RC (ed). Edinburgh: Churchill Livingstone, 1985; pp 223.

2 Shields JA, Wareng GO, Monto LG. Ocular findings in leprosy. Amer J Ophthal 1974; 77: 880-90.

3 Lamba PA, Santhoshkumar D, Arthanariswaran R. Ocular leprosy: a new perspective. Lepr India, 1983; 55: 490-4.

${ }^{4}$ Leprosy, vol. I. Dharmendra (ed). Bombay: Kothari Medical Publishing House, 1978, pp 153-9.

5 Spaide R, Nattis R, Lipka A et al. Ocular Findings in Leprosy in the United States. Amer J Ophthal, 1985; 100: $411-16$

6 Sheskin J, Zauberman H. Iridocyclitis in lepra reaction treated with thalidomide, Lepr Rev, 1970; 41: 233.

7 Ramu G, Ramanujam K. Reactive States in lepromatous leprosy. Lepr India, 1964; 36: 3.

8 Dutta RK. A study of patients with ENL syndrome. Lepr India, 1979; 51: 209.

9 Christian M. The epidemiological situation of leprosy in India. Lepr Rev, 1981; 52 (Suppl. 1); 35-42.

10 Cochet MM, Bonnet R. L'esthesiometrie corneenne. Realisation et interet pratique. Bull Soc d'Ophthalmol, 1961; 541-50.

11 Swift T, Bauschard F. Pupillary reactions in lepromatous leprosy. Int J Lepr, 1972; 40: 142.

12 Cogan DG. A simplified entoptic pupillometer. Amer J Ophthalmol, 1941; 24: 1431.

13 Ostler HB. The Immunology of Hansen's Disease. In Immunological Ocular Disease. Friedlaender MH, Thabbara KF (eds). Int Ophthalmol Clin, 1985; 25: 2, 122. 
${ }^{14}$ Lamba PA, Rohtagi J, Bose S. Factors influencing corneal Involvement in leprosy. Int J Lepr, 1987 ; $55: 667$.

15 Brown S. Further studies on pathophysiology of Keratitis Sicca. of Rollet. Arch Ophthal, 1970; 83: 542.

16 Ffytche TJ. Role of iris changes as a cause of blindness in lepromatous leprosy. Brit J Ophthalmol. 1981; 65: 231-4.

17 Reath, Levan NE. Erythema Nodosum leprosum in a general Hospital. Arch Dermatol, 1975; $11: 1575$.

18 Ridley MJ, Ridley DS. The immunopathology of ENL:the role of immune complexes. Le pr Rev, 1983; 54: 95.

19 Marak GE, Jr, Front RL, Ward PL. Fluorescent antibody studies in experimental lens induced granulomatous endophthalmitis. Ophthalmol Res, 1977; 9: 317.

20 Gamble CM, Aronson SB, Breslia FB. Experimental uveitis: I. Production of recurrent immunologic uveitis and its relationship to increased uveal vascular permeability. Arch Ophthalmol, 1970; 84: 321.

21 Harboe M. The immunology of leprosy. In Leprosy, Hastings RC (ed.). Edinburgh: Churchill Livingstone, 1985; 77-8.

22 Hashizuma H, Shionuma E. Electron microscopic studies of lepromatous changes in iris. Int J Lepr, 1965; 33: 61.

${ }^{23}$ Weekeroon L. Ocular leprosy in Ceylon. Br J Ophthalmol, 1969; 53: 457. 